\title{
Empresas na sociedade nacional \\ e na sociedade local: perspectivas internacionais de análise da empresa*
}

\author{
Paola Cappellin** \\ Paula Menezes***
}

\section{Resumo}

A reflexão que guia este artigo é atualizar a análise sociológica da empresa, pela teoria do embeddedness. Abandonamos a visão mecânica da combinação entre necessidade e utilidade da grande empresa fordista para adotar a perspectiva de ver esta organização como complexa construção histórica (GRANOVETTER e MCGUIRE 1998, MINGIONE, 1999). Para isso, o artigo faz uma revisão da contribuição da literatura italiana e francesa, desde os anos 1980, que sugere mergulhar sobre a relação entre economia e sociedade. Nas conclusões, apresentamos elementos para atualizar estas discussões, especialmente no que tange à dinâmica empresa-território. Propõe-se observar os limites e possibilidades desta literatura, que a partir do conceito de embeddedness, historiciza as interpretações dos fenômenos econômicos.

Palavras-chave: empresa, desenvolvimento local, economia e sociedade, embeddedness.

\section{Introdução}

$\mathrm{O}$ ponto de vista das relações entre a economia e a sociedade sugere refletir sobre a imagem da empresa como parte da sociedade, nacional e local. Estaríamos hoje lidando com o abandono

* Este texto é um dos produtos da pesquisa em curso "A expansão da igualdade de oportunidades no território: trabalho e direitos numa perspectiva de gênero". UFRJ / CNPQ (2008-2010).

*** Professora do Programa de Pós-Graduação em Sociologia e Antropologia da Universidade Federal do Rio de Janeiro. Endereço eletrônico: cappellin@ uol.com.br.

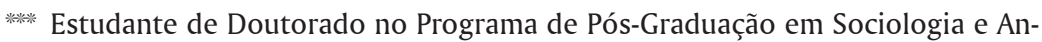
tropologia (PPGSA/UFRJ). Endereço eletrônico: menezes.paula@gmail.com. 
da imagem tradicional que a considerou agente econômico movido pela utilidade individual e pela necessidade de competir durante o longo período da produção em massa de tipo fordista ${ }^{1}$ ? Olhar a empresa como ator social, que maximiza o crescimento e a rentabilidade, se combinaria com a análise da diversidade de interações que a põem em contato com o entorno social, jurídico e político, pelos contratos escritos ou pactuados, as trocas formais e informais, as colaborações, as dinâmicas de confronto e de negociação? Reatar a empresa ao contexto do território nacional e local é uma perspectiva de análise que não é nova, mas retorna com maior pujança, quando as modalidades de industrialização descentralizada, não-fordista e flexível, se expandem. A reflexão que guia este artigo é proporcionar subsídios para atualizar a análise sociológica das empresas, pela teoria do embeddedness, (GRANOVETTER,1985) abandonando a visão mecânica da combinação entre necessidade e utilidade da grande empresa para adotar a perspectiva de sua complexa construção histórica (GRANOVETTER \& MCGUIRE, 1998; MINGIONE, 1999). Desta forma, passado e presente cultural, social e jurídico poderiam subsidiar o estudo do agir da empresa, interpretando-a pela sua imersão na configuração das relações sociais (Gramsci, 1950).

A empresa como conjunto complexo, em suas conexões contínuas com o seu entorno, absorve e renova tradições e fomenta inovações. As modalidades de organizar seus interesses materiais, expor e defender suas expectativas de ganhos concorrenciais, de responder às legislações e normas sociais, demonstram o quanto neste espaço social se explicita a prerrogativa de fazer escolhas. A empresa se apresentaria, assim, como um ator social ativo. $\mathrm{Na}$ história da industrialização, a convivência das práticas econômicas com relações extra-econômicas, tem permeado não só a transformação do projeto econômico de fazer empresa. Não é por acaso

1 Estamos nos referindo à crise da produção em massa de tipo fordista nos apoiando nas referências de G. Arrighi, isto é, a crise do "sistema de máquinas especializadas, operando no interior de empresas gigantescas, com integração vertical e administração burocrática". Por outro lado, o autor faz referência ao quanto esta crise possibilita o ressurgimento de sistemas de especialização flexível, executadas por unidades empresariais coordenadas por processos de troca através do mercado, denominadas como empresas "pessoais ou familiares”. (Cfe. ARRIGHI, (1996), PIORE e SABEL (1984) e HARVEY (1989)). 
que as formas de manufatura, de grande empresa fordista e a industrialização flexível, revigorada pela globalização, referemse não tanto e não só às mudanças históricas da organização das estruturas produtivas, mas, entre outros, à diversidade de como as empresas integram-se ao denso ambiente societal. A adesão às regras conforma-se à legislação trabalhista, às normas, aos standards de performance; o pagar os impostos, atender às preferências e exigências dos consumidores, são todas fontes de solicitações que evidenciam o quanto se renovam os constrangimentos coletivos que disciplinam sua potencial liberdade, quanto variados são os mecanismos para adaptar a produção a demandas de convivência social (TOURAINE, 1999).

As reformas institucionais em vários países, "modernizando a relação entre o estado e a sociedade” (EDWARDS \& HUPE, 2000), têm sido enfatizadas pela literatura não só porque fomentam a reestruturação das instituições, mas também porque envolvem a atualização dos mecanismos de descentralização do poder local. A reorganização das competências das autoridades municipais ${ }^{2}$, regionais, estaduais realça as contínuas alterações do formato das responsabilidades de planejamento econômico e de desenvolvimento das empresas. Neste contexto, explicitam-se modificações do conteúdo da luta política, dos projetos e das alianças entre público e privado nos territórios ${ }^{3}$. Estas transformações e reformas sugerem repensar como a empresa fordista tem se imposto ao território. Por muito tempo, a grande empresa foi representada, e se representou na sociedade, como autárquica, autônoma, livre das tradicionais sedimentações sociais (GRAMSCI, 1950). Sua liberdade manifestava-se na localização de seus empreendimentos, na discricionariedade de

2 Na Itália, a reforma de 1993, com as eleições diretas dos prefeitos (sindaci) é uma referência importante para reforçar o planejamento econômico local. Ver para Itália a contribuição de Trigilia (2007), para França, Structure and operation of Local and Regional Democracy Series (http://book.coe.int); para a Inglaterra, Mark Goodwin e Joe Painter (1996).

3 O estudo de Mark Goodwin and Joe Painter (1996) sobre a descentralização na Inglaterra desde 1970 é um bom exemplo para compreender as complexas dinâmicas da regulação que atingem a produção fordista mas também as competências das autoridades públicas locais, o local government, e a participação de agências, entidades e instituições (privadas) que formatam a local governance. 
determinar seus interlocutores diretos, em estimular a formatação do seu exército industrial de reserva, em escolher e definir suas formas de expansão, de crescimento, de inovação, apoiando-se pela pretensão de sucesso a ser alcançado no mercado. Não por acaso falava-se do projeto civilizatório da empresa (GRAMSCI, 1950) e da "organização fordista da economia” (TRIGILIA, 2007).

No século XXI, os desafios da crise não são exclusivamente econômicos. Ao aparecer neste momento também a crise da forma de regulação social (CASTEL, 1998), fica evidente o conjunto de processos que tornam possível contestar a antiga autonomia da empresa fordista (outorgada entre outros, pela sua ação no mercado) e suas formas de seletividade graças às quais se manifestava sua liberdade de agir. A empresa legitimou-se por muito tempo pelos resultados decorrentes de seu crescimento econômico (propulsor de mecanismos de concentração e expropriação) e muito raramente pela capacidade de responder aos direitos e às "pretensões de direitos" (BOBBIO, 1986).

Hoje, pelos diferentes mecanismos de políticas descentralizadas, as empresas parecem estar sendo sempre mais interpeladas a integrar-se no complexo jogo da regulação social (CAPPELLIN, 2008). A difusão de iniciativas descentralizadas (os pactos territoriais para o desenvolvimento local, os pactos para a ocupação, as experiências de concertação social etc.) no início dos anos 1990, em vários países, foi lida como exemplo, já que se fragiliza a concepção da unidimensionalidade da perspectiva econômica ${ }^{4}$.

Para diversas correntes da literatura, os mecanismos de descentralização são propulsores de uma revisão de como se constrói o projeto econômico da empresa. Este é hoje imerso num espaço social plural. O processo de avaliação de preferências e de decisões, as próprias escolhas estratégicas não decorreriam exclusivamente da única opção gerencial. Assim, eventos e situações que moldam as tomadas das decisões econômicas são fruto de complexos acertos disciplinados por normas, são acompanhadas por êxitos e fracassos

4 No Brasil, a reforma de distribuição das competências entre as agências do Estado nacional para as regiões e os municípios, ocorreu após a promulgação da Constituição de 1988. 
de condutas de negociação e/ou de concertação. Proporcionam densos impactos e desafios para alcançar a pactuação, alimentando-se por situações de dialogo, mas também de confronto e até de manipulação e/ou violência. A adoção de ferramentas introduzidas pelas empresas (critérios de governança, canais de comunicação, formatação de códigos de condutas, instâncias de coordenação paritária, formas de monitoramento interno e externo, ouvidorias, etc.) sugere pensar que a empresa é uma organização que não é mais habilitada a estabelecer seu projeto econômico de forma autárquica ${ }^{5}$.

A perspectiva de atentar para o fomento de interações não econômicas - que envolvem o embeddedness das empresas na sociedade - ressalta quanto é possível pensar como seu agir é modelado pelo contexto nacional e local. As vias de territorialização, deslocalização e internacionalização, poderiam reforçar a sua liberdade de movimento ${ }^{6}$. Mas, por outro lado, as formas heterogêneas de fazer empresa, pelas dimensões e pela descentralização aliadas à concomitante ampliação de regras predispostas a regular sua inserção no território, denotam o quanto é premente a busca de proporcionar limites para a liberdade da empresa fordista em formatar seu projeto civilizatório.

$\mathrm{Na}$ busca de compreender os complexos processos que manifestam tensões entre a liberdade e a regulação social, cabe interrogar a literatura sociológica. Os recursos interpretativos aparentemente dirigiram-se a superar as simplificações de sua organização, até de sua imagem. De âmbito fechado, de espaço autônomo, de coordenação autárquica passa-se a considerar a empresa como espaço aberto, âmbito onde emergem práticas e estratégias de coordenação, de cooperação ${ }^{7}$, de negociação. Após o inesperado

5 Lembramos como exemplos a pesquisa em curso de R. Giffoni (2009) que assume como objeto as respostas da empresa Aracruz às criticas promovidas pelos movimentos e grupos sociais a sua expansão fundiária nos territórios regionais de ES, RJ. e RGS.

6 Ver P. Zarifian (1998)

7 Lembramos a importante distinção entre a leitura econômica e a sociológica sobre a cooperação. Mingione (1999) aponta o quanto a cooperação, pela divisão do trabalho entre os economistas e os sociólogos, pode assumir um caráter paradoxal. As condições de cooperação como matriz dos comportamentos econômicos, condição de limite entre sociologia e economia, se adapta às opor- 
sucesso e expansão de formas não fordistas (a economia difusa, a industrialização de especialização flexível), a empresa é finalmente assumida como instituição aberta, dinamizada por mecanismos que a habilitam a agir / reagir / responder a injunções dos mercados e a interpelações presentes na sociedade. Desde os anos 1980, na França e na Itália ${ }^{8}$ há, na literatura, a preocupação de explicar a crise de expansão do modelo fordista, pela persistente reprodução de formas diversas de industrialização, pelo sucesso dos sistemas produtivos de médias e pequenas empresas, às vezes fomentados pela introdução de políticas públicas territoriais. Graças a estas, ou junto a estas, o objeto de estudo da empresa retorna a ser centro importante da reflexão da sociologia. O que fez da empresa um objeto sociológico no final dos anos 1980 ? O que representa a crise da concepção da empresa, de contexto fechado a ator social, na literatura sociológica? Estes aportes são ainda mais evidentes se os conectarmos com o avanço das preocupações do estudo sobre as transformações do mundo do trabalho revigoradas em períodos de crise do mercado internacional.

\section{As empresas na sociedade nacional: a literatura francesa}

No contexto nacional da França, no fim dos anos 1970, emerge um percurso intelectual que identifica as transformações das grandes empresas, pela saturação do mercado dos bens de massa, a intensificação de conflitos sociais no mundo do trabalho (desemprego, tensões nas relações industriais), impulsionadas pela maior competitividade de Estados Unidos e Japão. Estes desafios instigam alguns autores a inaugurar o estudo das organizações produtivas francesas

tunidades ofertadas pela competição econômica individualizada. Os sociólogos explicam como, a partir da diferenças sociais e culturais, o desenvolvimento da sociedade industrial pode saber incluir instituições, normas e processos nas preferências econômicas individualizadas.

8 A escolha da França e da Itália se justifica pela especificidade do tardio percurso industrial, frente ao exemplo da Inglaterra. A historiografia aponta a longa preservação, nestes cenários socioeconômicos, de formas diferenciadas de estruturas produtivas e de divisão técnica do trabalho, além de evidenciar as distinções das estratégias do patronato e da resistência dos trabalhadores. Ver M. Perrot (1978) e Sabel (1985). 
pela perspectiva da sociologia de empresa. Este é um enfoque analítico que emerge fortalecido pela definição da empresa

(...) .por ser um fato social, possuidora de uma dimensão institucional própria, uma vez que nela se formam e transformam as influências das instituições sobre as representações e as estruturas sociais. A empresa deixa de ser considerada um lugar onde os conflitos sociais se estabelecem, para emergir como espaço social de interações culturais (SAINSAULIEU \& SEGRESTIN, 1986).

Renaud Sainsaulieu e Denis Segrestin são os fundadores (junto a P. Bernoux, Michel Liu, Michel Bauer e Eugéne Enriquez) da assim denominada sociologia de empresa. O próprio A. Touraine (1992) manteve viva a preocupação de ver a empresa como um sistema social. Para ele a empresa é um agente da modernidade que entra em crise quando sua ação instrumental declina perdendo a exclusiva referência na orientação das práticas sociais produtivas. Segundo Touraine, nos anos 1960-1970 há uma explosão da modernidade racionalista, já que ocorre um grande distanciamento entre as condutas econômicas e as condutas culturais; entre a objetividade do mercado e a consciência subjetiva de pertencimento. Esta crise de coerência entre finalidades econômicas e condutas culturais desliza em fomentar uma nova concepção do espaço social: a empresa. Nela formatamse relações sociais abertas, manifestam-se renovações cultuais e projetos identitários que atingem esse específico espaço social.

No ano 1986, pela primeira vez, a revista francesa Sociologie du travail edita um número monográfico dedicado exclusivamente à empresa com a preocupação de "reabilitar a empresa no sistema social". É apontado por A. Borzeix o fato de que, durante muito tempo, para os sociólogos do trabalho na França, a empresa ficou como um lugar e não um verdadeiro objeto completo. A concepção de restringir a empresa ao lugar decorre:

1. da origem disciplinar da sociologia do trabalho que se colocou em posição crítica frente ao espaço da empresa "por ser esta a instituição central do capitalismo";

2. da divisão ideológica que separava quem estudava as organizações e seus dirigentes e quem estudava o movimento sindical, operário, e os conflitos de trabalho. 
A reabilitação da empresa é incentivada pelo conjunto de alterações internas à própria sociedade que impõem à sociologia repensar o papel que a empresa poderia desempenhar num momento particular da crise no final do século XX. Isto é, precisa reabilitar a empresa quando a economia e o emprego assalariado modificam a tradicional centralidade da forma fordista em ser motor de desenvolvimento. Esta até então tinha sido vista como uma célula microeconômica autônoma responsável pela produção de bens e serviços, que se ajustava (até com muita rebeldia) ao nível macro, à regulação social junto ao Estado-Nação e ao jogo de demandas solicitadas pelas associações de interesses (sindicatos dos trabalhadores e dos empregadores). Para estes autores, nos anos 1980, a empresa passa a ser interpelada para salvaguardar o emprego, e por extensão, para salvaguardar a sociedade. Renaud Sainsaulieu e Denis Segrestin no artigo "Em direção a uma teoria sociológica da empresa" (1986), apontam as novas exigências na sociedade francesa que permitem que a empresa possa ser assumida como objeto legítimo e apreendido do ponto de vista sociológico. Os autores aprofundam o sentido desta reabilitação da empresa por algumas situações:

1) frente à forte ênfase de autonomia e independência da autoridade da gerência que se apóia e se legitima no discurso da ciência da administração;

2) frente ao atual modelo evolucionista de seu crescimento que demonstra evidentes sinais de crise;

3) frente às experiências diferenciadas de novos processos de mudança do perfil fordista, produtivo e gerencial;

4) frente à simplificação ou invisibilidade de processos que estão gerando e fomentando diversificados conflitos e novas dinâmicas sociais de concertação social.

Reabilitar a empresa é reagir ao discurso da ciência da administração que prossegue considerando a empresa como "um lugar social auto-criador" e auto regulado, onde a gerência é o único agente capaz de enfrentar a salvaguarda do emprego. Com efeito, o discurso da gerência ao apelar à adesão dos trabalhadores para aprimorar sua participação no projeto definido pelo empresariado, busca reordenar unilateralmente a melhoria das funções. É assim atribuído 
ao poder da gerência mudar os papéis e os ambientes; é assim sugerido que as relações sindicais fomentem o consenso e menos a contestação. Frente a esta forte ênfase da abordagem administrativa que busca legitimar e valorizar a autonomia da empresa, os autores fazem sua primeira importante sugestão, para fundar a sociologia da empresa: "A empresa é expressão de muitos; isto é, a empresa é uma modalidade de ação coletiva que deveria estar apta a colocar em confronto o discurso gerencial com a riqueza das propostas de reivindicação" (SAINSAULIEU \& SEGRESTIN, 1986).

A empresa é reabilitada porque é considerada como espaço onde se formam dinâmicas que incentivam contínua elaboração de identidades (identidade nacional, local e de classe). É ambiente plural onde a presumida cultura de empresa é substituída por contínuos arranjos de interações sociais; enfim, como espaço de relações entre regulação econômica e ação coletiva. A elaboração de identidades na empresa justifica-se pela criação e pelo encontro de atores diversos que convivem formatando formas distintas de cooperação (da manufatura à empresa capitalista). Deste enunciado emerge com clareza que a organização e a gestão são frutos do confronto de comunidades profissionais diferenciadas (os diretores, os engenheiros, os operários em suas várias qualificações, os trabalhadores manuais etc.) que chegam a uma cooperação. Com frequiência, a ciência da administração nega estas comunidades pela aceitação do comando da gerência.

A percepção da sociologia de empresa desmistifica, ou melhor, quebra a referência auto-centralizada da empresa. Essa imagem foi por muito tempo pensada por expressar um único vínculo simbólico, de valores compartilhados, que conferia um sentimento de pertencimento, uma capacidade coletiva de produzir, um consenso em volta do projeto montado pela gerência. Se a ciência da administração está propensa a ressaltar uma comunidade de trabalho, para os autores, esta é uma hipótese paradoxal. Com efeito, reabilitar a empresa significa manter ativa a vontade intelectual de tornar plurais as realidades culturais que se confrontam no interior da organização/ empresa. Isto é, a cooperação é fruto de interações entre grupos profissionais hierarquicamente posicionados. Na organização, estes grupos confrontam a definição do qual será o projeto de empresa, as 
referências de comunidades, de saberes, de histórias identitárias. Nestes termos, até a própria definição de eficácia é uma expressão do contrato entre atores posicionados diferentemente na estrutura hierárquica da organização.

Finalmente, a contribuição da sociologia da empresa é estudar esta organização como espaço social, capaz de produzir efeitos na sociedade, seja pelas fontes de representações coletivas, seja por ser um ambiente propiciador de relações sociais. Os autores se perguntam se estudar as empresas ajudaria a identificar e conhecer dinâmicas sociais que inovam as relações sociais na sociedade; se as interações culturais formatadas na empresa são capazes de estimular processos positivos de mudança social. Esta inquietação é complexa por que a perspectiva sociológica se desloca do olhar analítico para absorver uma percepção mais conjuntural. A saber: a crise industrial européia face à concorrência mundial, dos EUA e do Japão, coloca o quanto é ampla a erosão dos mercados disponíveis às empresas européias. Por outro lado, a emergência da alta taxa de desemprego demonstra a urgência de ajustar os antigos modelos de desenvolvimento que se apoiavam no pleno emprego. Sainsaulieu (1995) aponta o quanto a cultura de empresa mascara as diferentes interações culturais, já que a empresa é um espaço social de contínuos confrontos, de contínuas tomadas de decisões, onde a força de poder hierárquico nem sempre deixa espaço para as resoluções negociadas ou pactuadas. Sob essa ótica, o projeto de empresa apresenta-se como arena bastante movimentada já que emergem situações onde o debate é incentivado ou é ofuscado; onde os sujeitos políticos que participam podem ser excluídos, afastados, silenciados, ou cooptados. Toda e qualquer decisão, para esta abordagem, é fruto de práticas que colocam na sociedade nacional, frente a frente, projetos de conservação e projetos de inovação.

\section{As empresas na sociedade local. A literatura Italiana}

Na Itália, diferentes grupos de pesquisadores incentivados pelo êxito de áreas concentradas de formação de "empresas pessoais ou familiares" (ARRIGHI, 1996) introduzem, desde os anos 1980, algumas categorias para explicar o desenvolvimento de formas não- 
fordistas de produção: a industrialização sem fraturas e a economia de industrialização difusa.

A industrialização sem fraturas (FUÁ, 1983) registra formas que contrastam com as áreas das grandes indústrias onde se concentra grande contingente de mão-de-obra desvinculada de suas origens; onde os vínculos e as relações familiares permanecem como centro unitário de funções e decisões econômicas e sociais. A economia de industrialização difusa (CAPECHI \& PESCE, 1978) formou-se em realidades regionais não capturadas pela hegemonia do fordismo. Lembramos que Sabel (1985) pensou a Itália como exemplo para reforçar a idéia que a sociedade industrial não elimina, com o tempo, todos os vestígios das condições institucionais prévias ${ }^{9}$. Durante muito tempo, cada nação conserva marcas históricas de seu passado industrial ${ }^{10}$. A heterogeneidade do mercado de trabalho, vinculando-se à funcionalidade desempenhada pela empresa familiar, afasta a interpretação residual da empresa não-fordista na economia moderna. A formação de empresas "pessoais ou familiares" (ARRIGHI, 1996) não é um contexto estagnante, pouco dinâmico, caracterizado por baixos salários e por uso de técnicas produtivas tradicionais ou atrasadas. Muito pelo contrário, a própria capacidade de permanência, no tempo, desta malha industrial sugere que é necessário evidenciar os fatores estruturais que garantem seu equilíbrio e sua relativa impermeabilidade à concorrência das indústrias de grande porte. Há funções estruturais da economia de industrialização difusa, sobretudo no setor têxtil e metalúrgico. Capecchi e Pesce, em diversos relatórios e artigos publicados ao longo dos anos 1970 e 1980, reconstroem o êxito da industrialização difusa, experiência regional da Emilia Romagna. Esta região revitalizada desde o fim da primeira guerra mundial, opõe-se e contrasta com o modelo industrial do triângulo (Milano, Genova e Torino), espaço da grande indústria de marca fordista. Alimentam a industrialização difusa, sobretudo no setor metalúrgico:

9 Ver Cappellin (1999).

10 Para E. Mingione estas formas podem ser "condições histórico-sociais de embeddedness, desmistificando o modelo único do utilitarismo atomizado, do motor universal das preferências econômicas" (MINGIONE, 1999, p.13) 
- a solidariedade e a cooperação no interior dos núcleos familiares de agricultores sem terra;

- o regime de mezzadria (meação);

- as estratégias entre as gerações que sabem perpetuar a ética do trabalho autônomo, isto é, a recusa do trabalho dependente no seio da classe operária e;

- a presença de centros de difusão da cultura técnica que alimentam nas cidades a criatividade da formação de quadros inseridos nas organizações industriais de pequeno porte.

A industrialização difusa é assim caracterizada por algumas modalidades: a difusão por adaptação-filiação-imitação; a descentralização e a especialização de atividades, e os subsistemas industriais integrados. Da figura do ex-meeiro e ex-trabalhador assalariado, fruto de um lento e coletivo projeto familiar de mobilidade social, emerge a do pequeno empresário.

Arnaldo Bagnasco (1977), num estudo que se situa na interseção entre a economia e a sociologia, observa a especificidade sócioeconômico-política ${ }^{11}$ das regiões da Itália Central, a Terza Itália. Esta ocupa na reprodução capitalista um espaço intersticial-periférico, sendo explicitada pela lógica difusa que preside as condições de existência das empresas não-fordistas italianas, que encontraram um terreno fértil em alguns espaços regionais italianos. Em estudo sucessivo, o autor retoma esta problemática da Terceira Itália enfatizando o quanto este fenômeno pode ser situado nas fronteiras entre uma explicação econômica e um contexto sócio/político. Do ponto de vista econômico, é situado entre as descontinuidades que inviabilizam a grande empresa de tipo fordista, já que esta exige geralmente uma demanda padronizada e estável no tempo. Enquanto fenômeno extra-econômico é interpretado "graças aos

11 Na literatura histórico-social italiana, a tradição gramsciana nunca deixou de ser referência. Em especial, o debate da questão meridional nos anos 1970 foi sendo revisitado por ser exemplo emblemático da manutenção renovada das disparidades no mercado de trabalho e, também, cenário para "testar" a complexidade das interações desta problemática com a dos modelos de desenvolvimento nacional e regional. 
sistemas locais que possibilitam a compatibilização das estruturas sociais originárias com as novas estruturas econômico-organizativas descentralizadas" (BAGNASCO, 1988). Os efeitos de longa duração, das formas institucionais originárias, se amparam no comércio internacional, na grande tradição de especialização artesanal, na estrutura familiar de produção e de finanças, na reduzida significação de desenvolvimento do proletariado urbano, nas relações cidade-campo graças à difusão do putting-out-system e, finalmente, na produção em pequena escala. Os patrimônios sócio/culturais são considerados as premissas da assim denominada "construção social do mercado" (BAGNASCO, 1988).

Esta literatura apóia-se na renovação contemporânea de formas iniciais do capitalismo italiano, da Idade Média e da Renascença, componentes importantes para preparar os pré-requisitos sociais deste modelo emergente nos anos 1980. Isto é, a herança histórica funciona como um recurso para interpretar a configuração do tecido industrial no fim do século XX, como alternativa à tradicional hegemonia da empresa fordista.

\section{As empresas e as políticas de desenvolvimento local}

Diversas iniciativas de políticas econômicas ${ }^{12}$, desde os inícios dos anos 1990, na Europa e na Itália, buscam superar a crise de competividade industrial fomentando a vertente do planejamento "negociado". Nestes contextos registra-se o chamado ao envolvimento sócio-político da empresa, já que lhe é solicitado saber integrar metas diversas, mas, não por isso, incompatíveis: a busca de acrescer a competitividade, a coesão social e a luta contra o desemprego. As políticas denominadas de "pactos territoriais" 13

12 Ver como primeiro documento, o Livro Branco da Comissão Européia “Growth, Competitiveness, Employment: The Challenges and Ways Forward into the 21st Century "-COM(93) 700, December 1993.

13 Lembramos que na Itália foram ativados tanto os pactos inseridos na legislação européia (1994-1998), quanto aqueles financiados pela legislação italiana. A denominação de "Patto territoriale" faz referência a uma metodologia de concertação onde cada agente econômico intervem como sujeito social assumindo as responsabilidades de fomentar e promover o emprego e o termo "territorial" delimita o espaço geográfico e político diretamente escolhido para valorizar 
são iniciativas que evidenciam o quanto as empresas são chamadas a aderir a uma cultura de relações pactuadas / concertadas que tem um impacto positivo também para aumentar as fontes de emprego ${ }^{14}$. Tudo parece sinalizar que finalmente a empresa poderia ser parte do contexto institucional ativo. Para compreender esta alteração, é mister detalhar o desenho destas linhas de incentivos.

A obtenção do auxílio público (europeu, estatal, regional e local) para implementar os projetos de pactos territoriais, depende das metas que estes se prefixam: aumentar a dotação de bens coletivos materiais (infra-estruturas) ${ }^{15}$ e bens imateriais (governance ${ }^{16}$, capital social, etc.) a favor de iniciativas integradas de desenvolvimento. A formatação destes programas reconhece a empresa como um dos sujeitos que pode demandar recursos junto às instituições públicas territoriais ${ }^{17}$. As empresas apresentam-se, nestes contextos, como atores que se envolvem para enraizar o desenvolvimento em conexão à vida de centros urbanos não metropolitanos ${ }^{18}$.

Pensando a literatura dos anos 1980, já resumida, podemos dizer que há uma clara continuidade da perspectiva de estudo:

os recursos endógenos. Ver: Commission Communication concerning the Structural Funds (1999) e Roberto Pedersini (1997).

14 Após cinco anos destas iniciativas no território italiano, em 2002, foi inaugurado um programa nacional de avaliação que envolveu as centrais sindicais (CGIL,UIL,CISL), além das associações do empresariado e o estado.

15 Por bens coletivos entendem-se bens de caráter indivisível, isto é, bens cujo acesso e uso não são reservados aos indivíduos isoladamente, mas que estão disponíveis para uma pluralidade de indivíduos, a assim chamada "coletividade de referência". Para os bens públicos não existem "regras de fechamento ou exclusão" de quem pode usufruir.

16 Por governance se entende um modelo de decision making que implica uma coordenação de tomada de decisão entre instituições públicas, organizações coletivas e atores privados. Neste contexto os recursos de autoridade, de controle hierárquico das instituções públicas são equilibrados pela presença de formas de concertação preocupadas em promover o consenso sobre as políticas e em promover a cooperação social.

17 Aos pactos manufatureiros se agregam aqueles com fins de introduzir serviços para valorizar "as novas fontes de ocupação" graças ao uso de infra-estruturas dirigidas: 1) a estimular a oferta de serviços às pessoas (por exemplo no Sangro Aventino; Napoli Nord-est); 2) a apoiar o setor não- profit; 3) a projetos de construção de casas para idosos e creches para infância (Napoli Nord-est; Alto Belice Corleonese); 4) para infra-estruturas esportivas e para o tempo livre.

18 Entre 1998 e 2001, na Itália foram assinados mais de 230 pactos. 
os vínculos da empresa com o contexto social do território local. A empresa é sempre mais considerada uma instituição numa perspectiva de ser parte do sistema sócio-político. Agora estes vínculos são ativados para desenhar um projeto de futuro, de desenvolvimento local.

As empresas são assim valorizadas como atores sociais quando se abre, em 1993, na União Européia, o debate do desenvolvimento local ${ }^{19}$ que se ampara no tripé: crescimento, competitividade e ocupação ${ }^{20}$. Articulam-se as prioridades: reforçar a competitividade do território europeu frente ao mercado mundial e proporcionar a coesão social, graças à tentativa de solucionar $\mathrm{o}$ alto desemprego. As experiências na Itália (desde 1998) concentramse, de um lado, para superar a degradação e empobrecimento de algumas áreas e, por outro, para aprimorar ou aumentar a distribuição do acesso de infra-estruturas com formas subsidiárias aos investimentos (públicos e privados) e, conseqüientemente, ampliar a oferta de emprego ${ }^{21}$. A exigência é produzir externalidades, isto é, introduzir vantagens com perspectivas de estimular a renovação das fontes de desenvolvimento local, entre outros, da instalação ou a modernização econômica industrial.

A formatação dos pactos reconhece que as empresas possam participar ativamente nos projetos de cooperação estratégicos, em benefício de frutos de longo alcance para a localidade ${ }^{22}$. Diferentes

19 A política européia sobre o desenvolvimento local se ampara nas diretivas "Growth, Competitiveness, Employment: The Challenges and Ways Forward into the 21st Century" -COM(93) 700 de 1993. Este documento dá ênfase a uma economia descentralizada, solidária, competitiva e faz explícita referência ao desenvolvimento local, fruto da responsabilidade e iniciativa ativa de instituições, empresários, forças sociais no território, segundo o princípio da parceria / coexistência compartilhada entre público e privado.

20 Inaugura-se a linha importante de financiamento pela via dos fundos estruturais. Ver: http://europa.eu/documents/comm/white_papers/index_it.htm.

21 Os investimentos subsidiados pelos programas de financiamentos dos pactos incluem: rede viárias, construção e urbanização de áreas industriais, intervenções para expandir os recursos elétricos, hídricos, para valorizar os recursos do território (museus, proteção de centros históricos, itinerários turísticos, etc.)

22 É reconhecida nesta moldura a referência de responsabilidade social das empresas, com particular conexão ao desenvolvimento de boas práticas, life-long learning, organização do trabalho, igualdade de oportunidades, inclusão social 
pré-requisitos são introduzidos a fim de que as instituições inseridas nas localidades possam pleitear estes benefícios e subsídios (de origem pública e privada). A atenção é dada não só aos clássicos atores (empresas, trabalhadores e seus representantes), mas também aos assim denominados micro-atores, isto é, os operadores engajados na montagem da política local: os homens políticos, os sistemas locais da administração, as prefeituras ${ }^{23}$, as associações da sociedade civil local. Por outro, há os macro-atores: o Estado, as entidades de representação setorial de empresas, os centros de pesquisa, as entidades de assessoria cientifica e tecnológica, de planejamento. Esses programas integrados são considerados "vindo de baixo" (bottom-up) já que os projetos deveriam ser construídos e estimulados pela cultura de planejamento compartilhada que combina recursos e prioridades definidas no contexto local 24 .

No plano operacional, a descentralização de insumos e os suportes emergem como recursos fundamentais de sustentação (o crédito, mercados de encomendas, as relações comerciais e técnicas de inovação). Estes insumos possibilitam a ampliação do campo de escolhas, permitem superar o mito do modelo fordista autocrático de empresa e, também, incentivam a racionalização de ações de cooperação e de coordenação - ativando iniciativas de sinergias entre as estruturas institucionais locais, partes ativas dos sistemas locais. Muitos dos projetos empresariais concernem à abertura de novas atividades produtivas (45\%), à ampliação das existentes (33\%), sua modernização ou reestruturação (13\%). A grande maioria dos projetos dirige-se às empresas manufatureiras, em comparação àquelas da agroindústria, turismo ou outros serviços. O grau de interdependência das finalidades varia muito segundo o tipo do pacto. Nos pactos manufatureiros, prevalecem projetos de tipo de

e desenvolvimento sustentável. Ver os documentos da programação negociada na fonte: http://www.uil.it/patti4.htm.

23 Voltamos a lembrar que a legislação n. 181 de 1993, ao estabelecer pela primeira vez na Itália a eleição direta dos prefeitos, é uma reforma que apóia a construção das políticas locais. Com efeito, o prefeito e os vereadores, em qualidade de "expertos”, aumentariam a arena dos atores da gestão econômica do território.

24 P. Magnatti, F. Ramella, C. Trigilia e G. Viesti (2005). Maiores informações, ver o documento "Os pactos territoriais". In: http://www.dps.tesoro.it/documentazione/docs/patti/RICERCA_PATTI_TERRITORIALI.pdf 
contexto (construção de infra-estrutura, hídrica e de estradas), enquanto nos pactos agroindustriais e turístico-culturais, a variedade das intervenções dirige-se a introduzir inovações de vocações.

A cooperação de empresas nestes programas evidencia quanto a sua adesão e quebra seu tradicional fechamento. Por outro lado, introduz a preocupação analítica de reduzir o enfoque individualista da racionalidade econômica. A evidente prática de sociabilidade dos dirigentes, a competência em saber lidar e promover uma cooperação entre atores diversificados, a importante versatilidade de fazer empresa (manufatura, turismo, agroindústria, serviços sociais e de apoio a segmentos específicos da população) pressupõem a saída do isolamento da instituição empresa.

A análise das interações pode fazer emergir como se formatam e se sustentam as diversificadas iniciativas técnicas, tecnológicas e comerciais locais que apóiam as relações das empresas com as instituições da sociedade local. Os pesquisadores que têm estudado desde o início dos anos 1980 as formas de cooperação entre empresas, a economia difusa e/ou a indústria de especialização flexível, se envolveram a acompanhar o movimento de adesão por parte das empresas a estes programas. Os autores, muitas vezes, recuperam o estudo dos recursos locais dispersos no território. Mas a partir de agora a análise destes recursos não está sendo vinculada ao passado artesanal, às origens agrárias dos saberes.

Lembramos que na origem de muitos distritos industriais monoculturais (anos 1970/ 1980), a literatura tinha feito referência à reativação da cultura de informação produtiva, técnica e comercial depositada no passado, às vezes muito longínquo. Por esta vertente havia claramente uma acentuada dependência da empresa em relação às tradições do território, ativada pela memória socializada no território. A sociedade local muda de lugar. Emerge por suas capacidades contemporâneas de intervenção, ressaltando a força da autonomia do território local. É reconhecendo as características do território que a empresa descobre ser ator ativo, que encontra as formas de interagir e de se integrar nos programas e políticas econômicas. Este maior poder da localidade tem a ver, dentre outros, com as reformas das atribuições de poder administrativo entre o Estado 
nacional, as regiões e as prefeituras ${ }^{25}$. O estudo do fomento dos pactos territoriais reitera, mais uma vez, a necessidade de abandonar a perspectiva fordista do projeto civilizatório da empresa.

\section{5. À guisa de conclusão}

O estudo das formas históricas nacionais e locais, seguidas pela configuração das recentes crises do modelo de empresa fordista, ao combinar-se com os aportes inovadores da sociologia incentiva o abandono da perspectiva clássica do predomínio da Economia sobre a sociedade. Isto é, do predomínio da visão atomizada do indivíduo e da empresa como agentes econômicos. A leitura clássica apoiava-se na força da combinação entre necessidades e utilidades da grande empresa. Neste modelo, o território local era um depositário de tradições do passado que precisavam ser remodeladas para moldar-se às exigências da grande empresa fordista, sempre mais autônoma em suas capacidades de civilização: introduzir a produção de massa; criar o mercado de trabalho; domesticar a mão de obra; introduzir o desenvolvimento no território. $O$ poder burocrático e despótico da empresa fordista desvalorizava as solidariedades tradicionais dispersas no território, por ser obstáculo à vitalidade inovadora industrial.

O que há de novo na literatura, após os anos 1980? A difusão das crises mundiais do mercado, o êxito econômico de áreas de formação de empresas "pessoais e familiares", a implementação de políticas descentralizadas (na Europa e em especial na Itália) apontam quanto os movimentos do mercado na fase atual incentivam a abandonar a exclusividade de um único modelo industrial para introduzir diferentes movimentos e diversas configurações. Uma primeira ruptura foi apontada pelos estudos que colocaram a ênfase sobre os capitais culturais e sociais herdados pela força do passado. A leitura do embeddedness das práticas econômicas foi um ganho analítico. Agora com a saturação do mercado estandardizado, aliada à crise da ocupação, à crise de fragilidade e pela deterioração do território, se potencializa a presença ou a ausência de capital social no território. Lembramos que o capital social tem

25 Ver nota n. 4 deste texto. 
sido adjetivado por diferentes correntes de pensamento. Putnam, em 1993, o considerou um importante recurso para evidenciar o quanto a força da civicness, como cultura cívica herdada, poderia proporcionar uma chave para o entendimento da mais alta ou mais baixa densidade de relações de confiança mútuas depositada nas localidades. A ausência de capital social demonstraria a dificuldade de superar, por exemplo, o tradicional caráter de isolamento do agir empresarial. ${ }^{26}$ Pensar o capital social nesta perspectiva é sublinhar a herança do passado, detectando quanto são difusas na Itália as bases individualistas, familistas, ou nepotistas que criam barreiras para entrar em contactos, estabelecer a confiança em processos de colaborações e de interação coletiva. Hoje, vários autores italianos (PISELLI, 2001; BAGNASCO, 2002; TRIGILIA, 1999) por capital social entendem a presença ou a ausência de uma cultura partilhada por sujeitos, num determinado território, que pode reduzir os comportamentos oportunistas e assim, incentivar ou frear as novas formas de cooperação. E mais, estes autores ressaltam que o capital social é uma referência para capturar o conjunto de relações hoje disponíveis para renovar e potencializar (por isso "capital") os recursos cognitivos, como as informações, ou as normas, ou a confiança. Em outras palavras, a existência de capital social corresponde à atual presença de uma cultura capaz de estimular os atores a realizar objetivos, não alcançáveis sem este capital. Assim, um território onde há uma disponibilidade coletiva e onde os atores interagem em redes de relações para a cooperação é portador de capital social. A cultura compartilhada não seria mais originada pela herança histórica, pela via da interiorização sedimentada de um passado comunitário. Mas é o resultado de práticas de sociabilidade, estimulado por novos contextos - sociopolítico e institucional - capaz de introduzir novas relações de cooperação.

Desta forma, atualizam-se as referências substituindo a força do passado para perceber a atual disponibilidade de constituir interações e práticas de sociabilidade. Poderíamos hoje adjetivar o

26 Lembramos que o agir empresarial por tradição foi durante muito tempo considerado individualista e por isso, isolado, com forte propulsão a se tornar autocrático. 
capital social pela intervenção que as instituições têm em mobilizar redes de relações (TRIGILIA, 2004, p.27). Isto é, estimular disponibilidades para cooperar, sob a força de normas de confiança mútua que abandonam o interesse individualista, que superam os vínculos tradicionais de resistência.

Assim, o território apresenta-se mais denso de referências para o sucesso empresarial: são os bens coletivos locais, vistos como economias externas para as empresas (TRIGILIA, 2004, p.15), que conseguem estender as cadeias de interações; é o aumento dos interlocutores, atores a serem contatados, que revigora o envolvimento, a mobilização, enfim a sociabilidade. As referências a Durkheim (1999) e sua concepção da divisão social do trabalho e de Granovetter (1985) sobre a perspectiva do embeddedness, a imersão e/ou incrustação da economia na sociedade, não são, neste momento, aleatórias. Os recentes distritos e o nascimento de empresas de tecnologia high tech ${ }^{27}$, com vocações para a biotecnologia, nanotecnologia, instrumentos tecnológicos para a medicina e aeroespacial, design industrial, sistemas inovadores para a produção e distribuição de energia, etc, se colocam como exemplos de instalações industriais que substituem o tradicional modelo dos distritos em setores das indústrias química, siderúrgica, têxtil, automotiva. Nestes novos contextos industriais, o capital social é recuperado como categoria descritiva. Mas, desta vez, é útil para identificar os elementos e as condições sociais inovadoras de disponibilidade de cooperação.

Tudo indica que as recentes realidades territoriais amparadas pela complexa malha de relações e de interações entre diversos atores atualizaram o quadro de referências. Agora as empresas pós-fordistas estão num contexto de ricas economias externas que as ajudam a competir num clima de concorrência acirrada. Isto não ocorria com a fábrica fordista, com sua produção estandardizada e constante. Esta conseguia ganhar a competição de preços, por critérios e escolhas próprias. Quanto mais a localização fordista estava em contextos pobres de recursos e de bens coletivos locais, mais seus investimentos eram importantes. Ela se apresentava pelos investimentos que ela depositava no território, mas também por

27 Para a realidade italiana, ver: http://www.distretti-tecnologici.it/home.htm. 
seus vícios autoritários que, em conjunto, formavam sua presença civilizatória da sociedade local.

Hoje, as mudanças ressaltam a importância da dispersão das empresas nos territórios. Aumenta a dependência da empresa ao território para produzir e para ter acessos e usufruir de serviços e bens coletivos locais. Por estes diferenciados papéis - de produzir, mas também de usufruir de serviços - as formas de regular o comportamento atingem os agentes econômicos, as empresas, de forma a responder a regras e normas bem mais complexas e articuladas que acabam aumentando seus vínculos com as instituições nos territórios. Elas devem saber atender as exigências - por exemplo, do tratamento do lixo, do respeito da legislação trabalhista, etc -, para obter crédito. Mas também para poder usufruir de bens coletivos locais lhes é exigido, por exemplo, não depredar o patrimônio ambiental ou artístico local, ou algumas contrapartidas, como reduzir tarifas para atender os consumidores individuais residentes no território, etc, já que o consumo é de muitos usuários (a formação e a assistência social são dois setores dos assim chamados bens públicos abertos). Como consequiência, a força disciplinadora das normas locais que as empresas devem atender se multiplica.

A bibliografia internacional apresentada é uma fonte de inspiração para prosseguir a leitura da imersão, introduzindo a teoria do embeddedness das práticas econômicas / empresariais. Mas, por outro lado, esta literatura nem sempre aprofunda a análise da cooperação quando estão presentes, no território, atores portadores de interesses e necessidades desiguais e/ou conflitantes. As disparidades de poder são expressões de antagonismos que freiam a vontade de cooperação ou a realização de concertação.

$\mathrm{Na}$ literatura internacional parece frágil a atenção dada às tensões entre interesses conflitantes, ao clima político que pode frear ou impossibilitar a introdução de iniciativas de cooperação ou de políticas de desenvolvimento concertadas, como a palavra aponta, fruto de ações de pactos sociais ${ }^{28}$. Estas dinâmicas são

28 A bibliografia desta avaliação é bastante extensa. Ver: La lezione dei Patti territoriali per la progettazione integrata territoriale nel Mezzogiorno. In: http://www. dps.tesoro.it/documentazione/docs/patti/RICERCA_PATTI_TERRITORIALI.pdf. 
relativamente laboriosas já que se referenciam a interações, à formatação de redes de cooperação entre diversificados sujeitos públicos e privados. Como se moldam e se transformam as relações quando há interesses conflitantes, quando preexistem relações de poder? Como são encaminhados os pactos e como são solucionados os conflitos de interesses no território? Não haveria na literatura européia um abandono da análise da força de práticas autoritárias que resistem, registradas com tanta frequiência nos territórios locais? Caberia pensar a especificidade de contextos onde persiste a autoritarismo patrimonial e/ou a gestão empresarial paternalista, típicas expressões de territórios marcados por desigualdades sociais. Sob quais arranjos se chegaria nestes casos ao fomento de políticas locais, pela via da concertação social? A teoria do embeddedness contribui para historicizar as interpretações dos fenômenos econômicos, ao reafirmar o quanto a dimensão social (e, portanto, construída ao longo de um processo histórico) informa a prática econômica. Caberá prosseguir, em próximas reflexões, na análise da literatura que enfrenta a realização do desenvolvimento industrial local em espaços permeados por configurações de poder menos democráticas. Isto é, onde os patrimônios pessoais e familiares chegam a mobilizar a lógica da utilidade individual e manifestar sua arrogância de se impor no território.

\section{Bibliografia}

ARRIGHI, G. O longo século XX. São Paulo: Contraponto/UNESP, 1996.

BAGNASCO, A. Tre Italie. La problematica territoriale dello sviluppo italiano. Bologna: Il Mulino, 1977.

BAGNASCO, A. La construzíone sociale dei mercato. Bologna: II Mulino, 1988.

. Il capitale sociale nel capitalismo che cambia. In: Stato e Mercato, n.65, 2002. 
BOBBIO, Norberto. Era dos direitos. Rio de Janeiro: Campus, 1996.

CAPECCHI, V. \& PESCE, A. Classe operaia e cultura borghese. Ipotesi di una ricerca in Emilia Romagna. In: Famiglia operaia, Mutamenti culturali, 150 ore. Bologna: Il Mulino, 1978.

CAPPELLIN, P. Mercado de trabalho e reconversão produtiva: uma revisão da literatura sociólogica italiana após os anos 1970. Revista Contemporaneidade e Educação (IEC - Instituto de Estudos da Cultura e Educação Continuada) - n.1., 1999.

. Politiques d égalité des chances: les grandes entreprises en Europe et au Brésil. In: HIRATA, H.; LOMBARDI, M.R. \& MARUANI, M. (Org.). Travail et genre, comparaisons internationales. Regards croisés Europe - Amérique Latine. 1 ed. Paris: La decouverte, 2008.

CASTEL, R. As metamorfoses da questão social: uma crônica do salário. Rio de Janeiro: Vozes, 1998.

DURKHEIM, E. Da divisão do trabalho social. São Paulo: Martins Fontes, 1999.

EDWARDS, A. \& HUPE, P. France: a strong state towards a stronger local democracy? In: DAEMEN, H. \& SCHAAP, L. Citizen and city. Developments in fifteen local democracies in Europe. Delft: Eburon, 2000. Disponível: http://publishing.eur.nl/ir/repub/ asset/758/BSK033.pdf.

FUÁ, G. Industrializzazione senza fratture. Bologna: Il Mulino, 1983.

GIFFONI, R. $O$ poder da crítica e as transformações nas estratégias sócio-territoriais da Aracruz Celulose. PPGSA/UFRJ, mimeo, 2009.

GOODWIN M. \& PAINTER J. Local governance, the crises of fordism and the changing geographies of regulation. In: Transactions of the Institute of British Geographers. New Series, Vol. 21, No. 4, 1996.

GRAMSCI, A. Americanismo e fordismo. In: Opere: Note sul machiavelli, sulla política e sullo stato moderno. Torino: Einaudi, 1950.

GRANOVETTER, M. Economic action and social structure: The problem of embeddedness. In: American Journal of Sociology, n. 91, pp. 481-510, November 1985. 
GRANOVETTER, M \& MCGUIRE, P. The making of an industry: electricity in the United States. In: The American Journal of Sociological Review, 1998.

HARVEY D. Condição pós moderna. São Paulo: Loyola, 2000.

ITÁLIA. Governo Federal - Tesouro Nacional. La lezione dei Patti territoriali per la progettazione integrata territoriale nel Mezzogiorno. In: http://www.dps.tesoro.it/documentazione/docs/ patti/RICERCA_PATTI_TERRITORIALI.pdf.

. Unione Italiana Del Lavoro. Lo sviluppo per il lavoro: i patti territoriali. In: http://www.uil.it/patti4.htm.

. Osservatorio sui distretti tecnologici. In: http://www. distretti-tecnologici.it/home.htm.

MAGNATTI, P.; RAMELlA, F.; TRIGILIA, C. \& VIESTI, G.. Patti territoriali: lezioni per lo sviluppo. Bologna: Il Mulino, 2005.

MINGIONE, E. Gli itinerari della sociologia economica in una prospettiva europea. In: Laville e Mingione (a cura di), La nuova sociologia economica. Prospettive Europee, Numero di Sociologia del Lavoro, N. 73, 1999.

PEDERSINI, R. Territorial pacts. A new form of decentralized social dialogue. http://www.eurofound.europa.eu/eiro/1997/04/feature/ it9704203f.htm.

PERROT, M. Les ouvriers et les machines en France dans la primeirère moitié du XIX siècle. In: Recherches n.32/33, 1978.

PIORE, M. \& SABEL, C.F. The second industrial divide: possibilities for prosperity. New York: Basic Books, 1984.

PISELLI, F. Reti. L'analisi di network nelle scienze sociali. Roma: Donzelli, 2001.

PUTNAM, R.; LEONARD, R. \& NANETTI, R. Making Democracy Work: civic traditions in modern Italy. Princeton: Princeton University Press, 1993.

SABEL, C. Trabajo y política. Madrid, Ministerio de Trabajo y Seguridad Social, España, 1985.

SAINSAULIEU, R. Les mondes sociaux de l'entreprise. Paris: Desclée de Brouwer, 1995. 
SEGRESTIN, D. \& SAINSAULIEU, R. Vers une théorie sociologique de l'entreprise. In: Sociologie du Travail, Paris, n. 3, 1986.

TOURAINE, A. Critique de la modernité. Paris: Fayard, 1992.

Vozes, 1999.

Poderemos viver juntos? Iguais e diferentes. Petrópolis:

TRIGILIA, C. Capitale sociale e sviluppo locale. In: Stato e Mercato, n.3, 1998 .

. Sviluppo Locale. Um progetto per L'Italia. Roma-Bari: Laterza, 2005.

UU.EE (Documento oficial da Comissão Européia). Growth, Competitiveness, Employment: The Challenges and Ways Forward into the 21st Century -COM(93), 700 de 1993.

. Documenti dell'Unione Europea. http://europa.eu/ documents/comm/white_papers/index_it.htm.

ZARIFIAN, P. Ver un Peuple-Monde?. In: Cahiers du Gedisst, Le paradoxes de la mundialisation. n. 21, 1998.

\section{Abstract \\ Business firms in national and local society: international perspec- tives for analysis of companies}

The reflections that this article provides are meant to develop a sociological analysis of businesses through a theory of embeddedness. We reject a mechanistic view of the way need and utility combine in the large Fordist firm, preferring to adopt the perspective that sees this type of organization as a complex historical construction (Granovetter e McGuire 1998, Mingione, 1999). For such purposes, our article reviews contributions of French and Italian literature which, as of the 1980s, has suggested the need to devote profound attention to the relationship between economy and society. In our conclusions, we present elements meant to bring these discussions up-to-date, particularly with regard to the dynamics of business firm and territory. We propose consideration of the limitations and possibilities of this literature, which through the concept of embeddedness has added historical dimensions to our understanding of economic phenomena.

Keywords: companies, local development, economics and society, embeddedness. 
